Ibrahim Alhoussain Khalil \& Omar saad Al- tmaran \& Abdulhamid essa Hashmi

Volume (4) No. (1) 2021

توظيف استراتيجية الصف المقلوب في صفوف الرياضيات بالمرحلة الابتدائية

د. إيراهيم بن الحسين خليل \& أ. عمربن سعد التمران\& عبدالحميد بن عيسى هاشمي 
د. إبراهيم بن الحسين خليل \& أ. عمر بن سعد التمر ان \& عبدالحميد بن عيسى هاشمي

\section{توظيف استراتيجية الصف المقلوب في صفوف الرياضيات بالمرحلة الابتدائية}

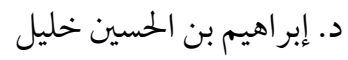

دكتوراه فلسفة التربية في تعليم الرياضيات، وزارة التعليم، تعليم صبيا، السعودية

i.kh2012@hotmail.com

$$
\text { أ. أعمر بن سعد التمران }
$$

طالب دكتوراه، جامعة الإمام محمد بن سعود الإسلامية، السعودية

aaa.1510@ hotmail.com

$$
\text { طالب دكتور اه، جامعة أم القرى، السعودية هاشمي }
$$

Hmid554@hotmail.com

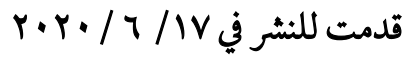

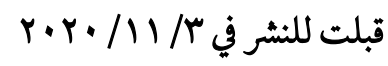

الملخص: هدفت الدراسة إلى التعرف على الانعكاسات الناتجة من توظيف استراتيجية الصف المقلوب

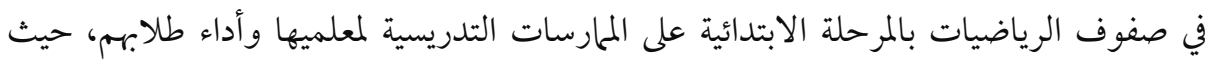

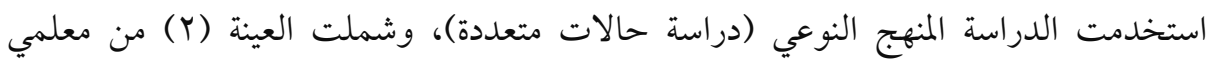

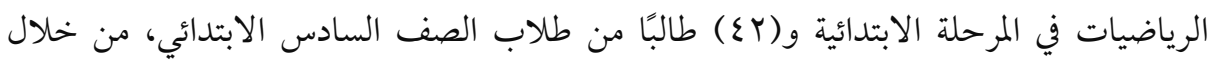

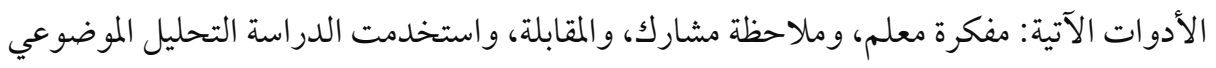
(الاستنباطي، الاستقرائي)؛ لتحليل البيانات، وتو صلت الدراسة إلى مجموعة (Thematic Analysis)

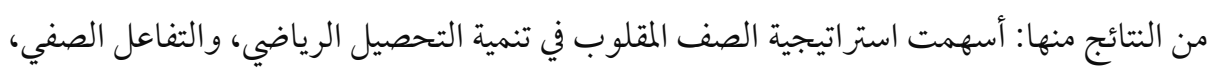

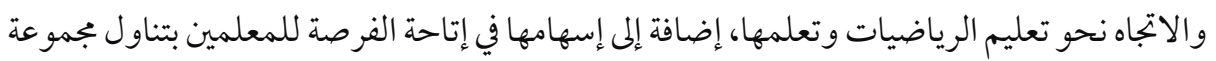

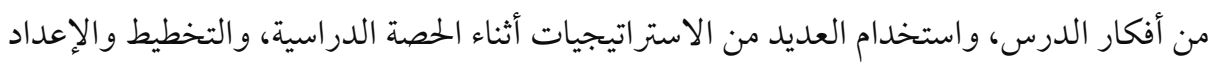
المناسب للدرس، وأوصت بأهمية تدريب المعلمين على توظيف التقنيات في تعليم الرياضيات، وإنتاج المقاطع المرئية (الفيديوهات) التعليمية لدروس الرياضيات. الكلمات المفتاحية: الصف القلوب - الرياضيات - المرحلة الابتدائية http://dx.doi.org/10.29009/ijres.4.1.12 


\title{
Employing the flipped classroom strategy in primary mathematics classes
}

\author{
Ibrahim Alhoussain Khalil
}

PhD in Mathematics Education, Mathematics Teacher, Saudi Arabia

i.kh2012@hotmail.com

Omar saad Al- tmaran

PhD Student in imam muhammad ibn saud islamic university, Saudi Arabia aaa.1510@hotmail.com

Abdulhamid essa Hashmi

PhD Student in Umm Al-Qura University, Saudi Arabia

Hmid554@hotmail.com

\section{Received in 17th June 2020}

Accepted in 3rd November 2020

\begin{abstract}
This study aims to identify the implications of using the flipped classroom strategy in the primary school in teaching practices of mathematics classes of mathematics teachers and their students. This study used a qualitative approach. The sample of the study consists of (2) mathematics teachers in the primary school and (42) students from the sixth-grade students. The study used the following tools: Teacher notebook, participant note, interview. The study used thematic analysis to analyze the data. The study reached a number of results, including: flipped classroom strategy contributed to the development of mathematical achievement, classroom interaction, the attitude towards teaching and learning mathematics. The flipped classroom strategy allowed teachers to take more of lesson ideas, use several strategies in the classroom, plan and prepare for the lesson. The study recommended: We need to train teachers to employ techniques in mathematics education, and to produce instructional videos for math lessons.
\end{abstract}

Key word: flipped classroom - Mathematics - strategy in primary 
د. إبراهيم بن الحسين خليل \& أ. عمر بن سعد التمر ان \& عبدالحميد بن عيسى هاشمي المجلد (4) العدد (1) 2021م

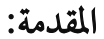

تهدف التطورات المتسارعة في بجال التعليم والتعلم، والمستجدات المتتابعة للرقي بمستوى الممارسات التدريسية؛ لتنعكس إيجابًا على شخصية الطلاب في مر احل التعليم المختلفة، وتسهم في تنمية التحصيل الدراسي، وتحقيق التنمية الشاملة لهم. تركز الاتجاهات الحديثة لتطوير العملية التعليمية على تنمية دور الطالب الإيجابي وقدرته على المشاركة والبحث والاعتماد على النفس (الدوخي، IV • (Y). ويعدّ دمج التقنية في التعليم عموماً-وفي تعليم الرياضيات خصوصًا- من التوجهات التي يؤمل عليها أن تنعكس إيجابًا على كلٍ من الممارسات التدريسية والتحصيل الدراسي وتطوير التفكير الرياضي لدى الطلاب. حيث تعد التقنية مبدأ من مبادئ تعليم الرياضيات وفقًا للمجلس القومي لمعلمي الرياضيات NCTM, 2000) National Council Of Teacher Of Mathematics) . موقد أشار

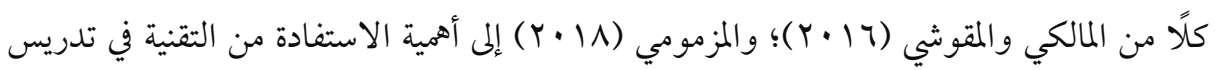
الرياضيات. ويعدّ استخدام التقنية من مهارات القرن الحادي و العشرين اللازمة لتطوير تعليم الرياضيات وتعلمها في المرحلة الابتدائية، ويمكن الاستفادة منها في تطوير المعرفة الرياضية لدى الطلاب؛ إذ تتيح للطالب التفاعل والمراجعة المستمرة لدروس الرياضيات (خليل والعمري، 9 (• ب؛ خليل، 9 1 • ب). ويعرف الرويس (11) التقبنية في تعليم الرياضيات بأنها استخدام أجهزة الحاسب المدرسية والشخصية، وما يلحق بها من البرامج والبربجيات التي تخدم تعليم الرياضيات. وتتعدد الطر ائق التي يمكن من خلالها توظيف التقنية في بجال تعليم الرياضيات وتعلمها، ومن ذلك توظيفها في استراتيجية الصف المقلوب، إذ تعتمد آلية الصفوف المقلوبة على تغيير دور المدرسة و المنزل في التعليم التقليدي الذي تُقََّّم المادة العلمية من المعلم، ثم يقوم الطالب بحل الو اجبات المطلوبة في المنزل، بينما يتغير دور الطالب في الصف المقلوب فيستعد الطالب ويطّلع على الفيديوهات والأفلام التعليمية المتعلقة بالدرس قبل الحضور للمدرسة، ويوجَّه الصف الدراسي لمجموعة من المهام منها:

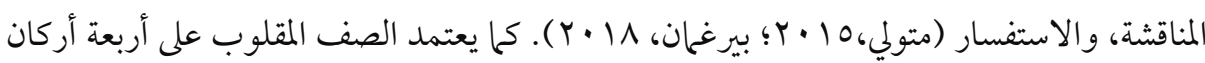


Uzunbylu \& ( رئيسة هي: البيئة المرنة، والثقافة التعليمية، والمحتوى التعليمي، والمعلم المحترف .(Prevalla, 2019 وتُقدَّم المعرفة في الصف المقلوب قبل الحضور للصف الدراسي؛ ليستفاد من الوقت في مساعدة الطلاب على استيعاب ما قرؤوه، أو شاهدوه، أو حاولو ا فهمه قبل الوصول للفصل (Farmer, 2018). ويعرف الصف المقلوب بأنه استراتيجية تعليمية يمكن أن توفر للمعلمين وسيلة لتقليل من التعليم المباشر عند التدريس مع زيادة التفاعل الصفي، وتتيح وقتًا إضافيًّ في الخصة الدراسية (Shafique \& Irwin-Robinson, 2015) نموذج تُنَّذّ فيه أنشطة الصف داخل الفصل، ويتميز عن الصف التقليدي بإمكان تنفيذ الأنشطة في كل مكان. وتؤكد استراتيجية الصف المقلوب على التعلم النشط من خلال التركيز على المتعلم؛ لزيادة جودة التدريس خلال الخصة الدراسية (Ozdamli \& Asiksoy, 2016). ومن العوامل المؤثرة في تبني استراتيجية الصف المقلوب معرفة المعلم باستخدام التكنولوجيا، Castilla Villaba \& Redondo- Duarte, وطر ائق التدريس، واتجاههم نحو الابتكار، والتنمية المهنية 2018). إن تصميم حصة دراسية بعناية من المعلم يؤثر في الاتجاه و اكتساب المفاهيم والمهارات الرياضية .(Foldnes, 2017) لذا فإن توظيف استراتيجية الصف المقلوب تتيح زيادة الوقت في الحصة الدراسية، والتفاعل الصفي، وفهم المعرفة الجديدة، والتنوع في الأنشطة، ومن أبرز تحديات الصف المقلوب ضعف معرفة Chen, Hew, K \& Lo, الطلاب للتعامل مع استراتيجية الصف المقلوب، والإعداد له من قبل المعلم .(2017; Pulley, 2018)

كما تتيح استراتيجية الصف المقلوب للمعلم استخدام استراتيجيات متنوعة أثناء الحصة الدراسية منها: تعليم الأقران، وحل المشكلات تعاونيًا، والبحث (Stöhr \& Adawi , 2018). وتتطلب الصفوف المقلوبة من المعلمين المتابعة والتوجيه والإرشاد ومعرفة العوائق التي واجهت الطلاب، ومن المهم أن يولي المعلم اهتمامًا أكثر بالطلاب المنخفضي التحصيل في الرياضيات، فقد يكونوا 
د. إبراهيم بن الحسين خليل \& أ. عمر بن سعد التمر ان \& عبدالحميد بن عيسى هاشمي

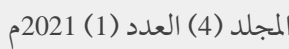

غير مستعدين للتفاعل مع الأنشطة والمحاضرات (Sun, Xie \& Anderman, 2018). والمهم أن يعيد Cabi, ) المعلم هيكلة بيئة التعلم وتنظيمها مع مر اعاة احتياجات الفرد والمجتمع والتركيز على المتعلم . (2018

إن توظيف استراتيجية الصف المقلوب له انعكاسات إيجابية منها: دعم مشاركة الطلاب، وتفاعلهم ورضاهم عن أدائهم (Fisher, Perényi \&Birdthistle, 2018)، وتزيد من فرص التعاون والمشاركة وزيادة المناقشات (Per \& Arne, 2018)، وتنمية مهارات التفكير العليا ( Lai \& Lee, 2017). إضافة إلى ذلك فإن توظيف الصف المقلوب يسهم في خفض القلق الرياضي، ورفع مستوى التحصيل الرياضي، ويجذب الطلاب لتعلم الرياضيات، ويسهم في تكوين اتجاه إيجابي نحو تعلم الرياضيات، ويدعم التعلم الذاتي، والتفكير الرياضي، ورفع مستوى الكفاءة الذاتية لتعلم Hwang \& Lai, 2017 Sun, Xie \& Anderman, 2018; Al-Hamdani \& Al Breiki الرياضيات

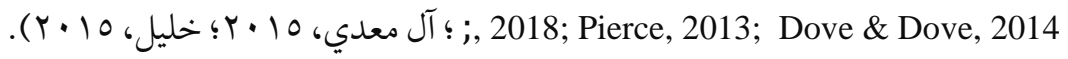
وللتحقق من فاعلية استراتيجية الصف المقلوب في تعليم الرياضيات وتعلمها أجريت العديد من الدراسات منها: دراسة شافيقو وارين روبنسون (Shafique \& Irwin-Robinson, 2015) التي استهدفت التعرف على فاعلية التدريس باستخدام الصف المقلوب في صفوف الرياضيات على التحصيل من وجهة نظر الطلاب في كلية سينتيال، استخدمت الدراسة الأسلوب الاستقصائي، واستُخدِمت أداتان للدراسة: هما استطلاع للرأي واستبانة، وشملت العينة ( •7) طالبًا، وتوصلت الدراسة إلى إيجابية التدريس باستخدام الصف المقلوب، وأوصت بأهمية إجر اء دراسات متتابعة حول توظيف الصف المقلوب. وأجرى ميور (Muir, 2015) دراسة هدفت إلى التعرف على وجهات نظر الطلاب وأولياء الأمور حول الصفوف المقلوبة في صفوف الرياضيات، واستخدمت الدراسة المنهج المختلط، والاستبانة والمقابلات الفردية والجماعية كأدوات للدراسة، وتوصلت الدراسة لمجموعة نتائج أهمها: أن توظيف الصف المقلوب يسهم في فهم المحتوى الرياضي، وإدارة الذات، ومر اجعة الدروس بسهولة. 
Ibrahim Alhoussain Khalil \& Omar saad Al- tmaran \& Abdulhamid essa Hashmi Volume (4) No. (1) 2021

بينلا استهدفت دراسة بهاغات وتشانغ وتشانغ (Bhagat, Chang \& Chang, 2016) التعرف على فاعلية الصف المقلوب في تنمية التحصيل الرياضي والدافعية لدى طلاب المرحلة الثانوية. استخدمت الدراسة المنهج شبه التجريبي، وأداتان للدراسة هما: اختبار للتحصيل الرياضي، ومقياس

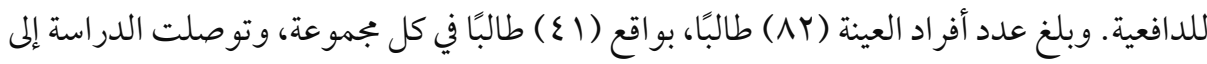
وجود فروق دالة إحصائيًا في التحصيل الرياضي والدافعية لدى المجموعة التي درست باستخدام الصف المقلوب.

وهدفت دراسة لي وهاوانق (Lai\& Hwang, 2016) إلى معرفة أثر التعليم المنظم ذاتيًا في الصفوف الدراسية المقلوبة في تحسين أداء الطلاب في الرياضيات بالمرحلة الابتدائية. واستخدمت الدراسة المنهج شبه التجريبي وأداتين للدراسة، هما: اختبار لقياس أداء الطلاب، واستبانة لقياس كفاءة التنظيم الذاتي، وبلغ عدد أفر اد العينة (ع ) طالبًا، ( • ) طالبًا في المجموعة التجريبية، و (ع ) طالبًا في المجموعة الضابطة، وتوصلت الدراسة إلى وجود فروق دالة إحصائيًا لصالح المجموعة التجريبة التي درست في الصف المقلوب من خلال التنظيم الذاتي، وأوصت الدراسة بأهمية مر اعاة التنظيم الذاتي عند تطبيق استراتيجية الصف المقلوب.

واستهدفت دراسة راما كريشنان وبر ايا (Ramakrishnan \& Priya, 2016) التعرف على فاعلية الصف المقلوب في تنمية التحصيل في وحدة المحيط والمساحة في مادة الرياضيات. استخدمت الدراسة المنهج التجريبي تصميم المجموعة الواحدة، وبلغت عينة الدراسة (•ع) طالبًا، وتوصلت الدراسة إلى وجود فروق دالة إحصائيًا عند مستوى دلالة ا • , •لصالح التطبيق البعدي، وأوصت الدراسة بتدريب المعلمين على إعداد دروس الفيديو لوحدات الرياضيات المختلفة والاستفادة من تطبيق الو اتساب.

بينما هدفت دراسة زيانقن (Zengin, 2017) إلى التعرف على مدى تأثير استراتيجية الصف

المقلوب بوساطة أكاديمية خان والمواقع المجانية المفتوحة في تنمية التحصيل الرياضي، ومعرفة وجهات نظر الطلاب حول الصف المقلوب. واستخدمت الدراسة المنهج المختلط، وبلغت عينة الدراسة (Y^) 
د. إبراهيم بن الحسين خليل \& أ. عمر بن سعد التمر ان \& عبدالحميد بن عيسى هاشمي

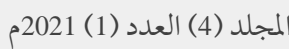

طالبًا من طلاب قسم الرياضيات، والاختبار التحصيلي والاستبانة المفتوحة كأدوات للدراسة،

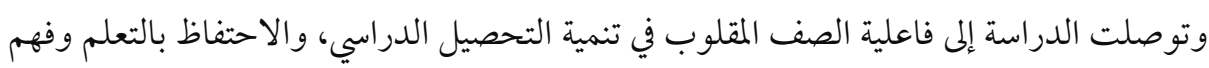

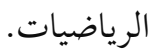

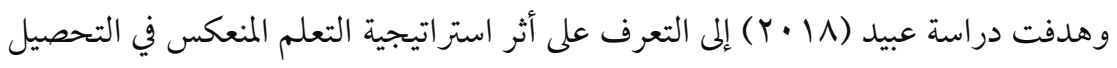

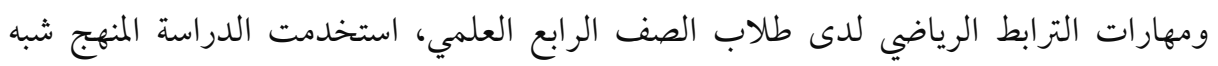

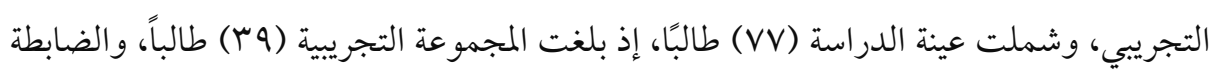

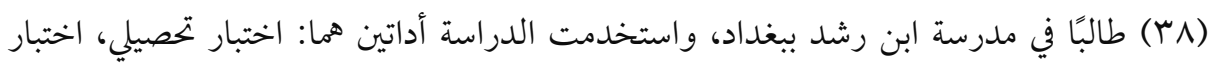
مهارات الترابط الرياضي، وتوصلت الدراسة إلى وجود فروق ذات دلالة إحصائية عند مستوى دلالة

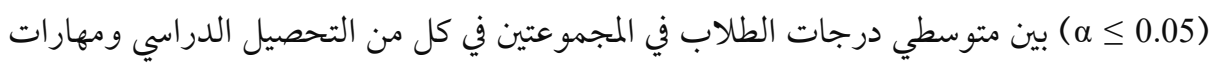
الترابط الرياضي لصالح المجموعة التجريبة.

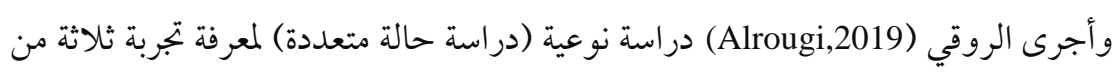

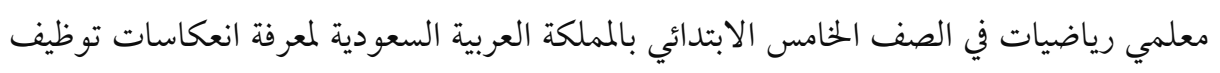

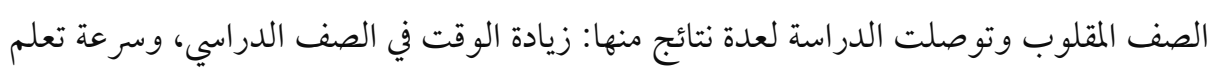

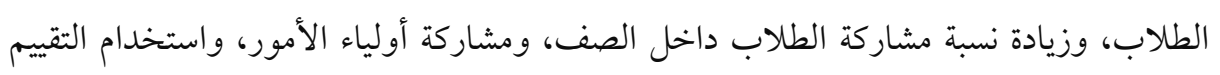
التكويني، وتطبيق المزيد من الأسئلة الهادفة.

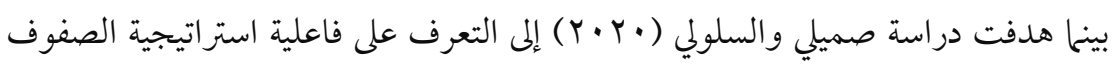

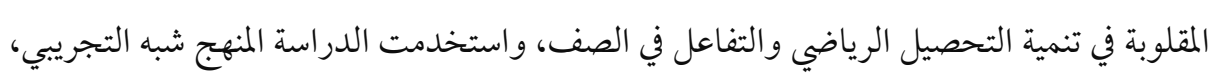
وتكونت عينتها من ( • ع طالبًا من طلاب الصف الثالث الثانوي بمحافظة صامطة، من خلالال أداتين

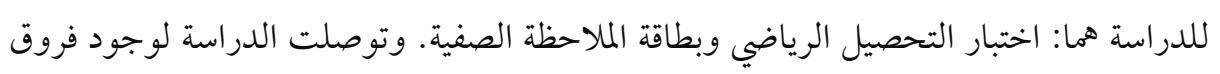

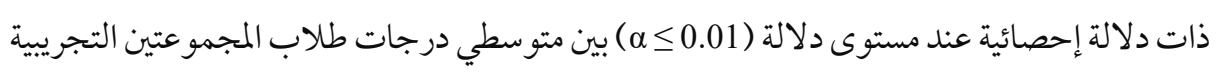

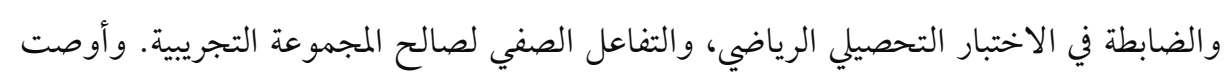


الدراسة بأهمية توظيف استراتيجية الصفوف المقلوبة، وتوفير المستلزمات اللازمة لذلك وإعداد مقاطع الفيديو.

وتأتي هذه الدراسة امتداداً للدراسات السابقة؛ للتعرف على أبرز الانعكاسات الناتجة من توظيف استراتيجية الصف المقلوب في صفوف الرياضيات بالمرحلة الابتدائية على الممارسات التدريسية لمعلميها وأداء طلابهم.

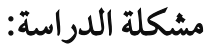

يعدّ دمج التقنية مبدأ من مبادئ تعليم الرياضيات المحددة من المجلس القومي لمعلمي الرياضيات بالو لايات المتحدة الأمريكية (NCTM, 2000)، إضافة إلى أنها مصدر أساسي تساعد الطلاب على التعلم، وإعطاء معنى للأفكار الرياضية، والتواصل والتفكير الرياضي وتنمية البراعة الرياضية (Kim \& Chang, 2010; NCTM, 2014). ويؤكد سيدقيو (Sedique, 2017) أنه من المهم أن يعي مسؤولو التعليم أهمية استخدام التقنية، وربطها بالمناهج وطرائق التدريس. إن البحث في الطر ائق والوسائل الداعمة لتنمية التحصيل الدراسي أمر في غاية الأهمية؛ إذ تشير

تنائج الاختبارات الدولية Trend in International Mathematics and Science Study [TIMSS] 2011, 2015

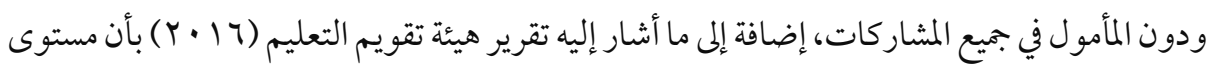
التلاميذ في المرحلة الابتدائية في الرياضيات متدني، وأن أداء (• ع ٪) من الطلاب كان أقل من الحد الأدنى. وقد أشارت دراسة العنزي و النذير (7 ( • r) إلى أن درجة اكتساب الطلاب في الصف السادس الابتدائي للمفاهيم الرياضية كان متوسطًا، ومنخفضًا في اكتساب المهارات الرياضية.

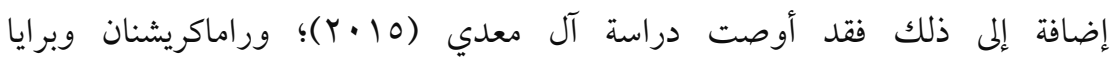

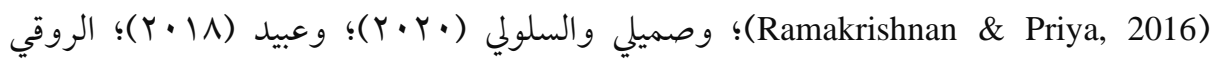
(Alrougi, 2019) 
د. إبراهيم بن الحسين خليل \& أ. عمر بن سعد التمر ان \& عبدالحميد بن عيسى هاشمي

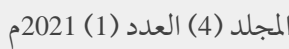

لتنمية التحصيل والتفكير الرياضي والتفاعل، إضافة إلى أهمية إنتاج الفيديوهات التعليمية لمواضيع الرياضيات المختلفة والاستفادة منها.

ونظرًا لخبرة الباحثين في تعليم الرياضيات في المرحلة الابتدائية على وجه التحديد وما لاحظوه من ضعف في التحصيل الرياضي، والتفاعل الصفي بالإضافة إلى القيام بدراسة استطلاعية تمثلت في مقابلة لمجموعة من معلمي الرياضيات ومشرفيها الذين أفادوا بضعف في تفاعل الطلاب وأولياء أمور هم مع معلمي الرياضيات، إضافة إلى تدني مستوى التحصيل الرياضي في الفصل الدراسي الأول

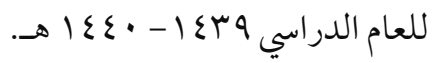

وبناء على ما سبق ذكره من مبررات جاءت هذه الدراسة؛ للتعرف على الانعكاسات الناتجة من توظيف استراتيجية الصف المقلوب في صفوف الرياضيات بالمرحلة الابتدائية على الممارسات التدريسية لمعلميها وأداء طلابهم.

أسئلة الدراسة: - n - n سعت الدراسة إلى الإجابة عن السؤالين الآتيين: الأول: ما انعكاسات توظيف استراتيجية الصف المقلوب في صفوف الرياضيات على الطلاب بالمرحلة الابتدائية؟

الثاني: ما انعكاسات توظيف استراتيجية الصف المقلوب في صفوف الرياضيات على الممارسات التدريسية لدى معلمي الرياضيات بالمرحلة الابتدائية؟

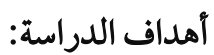
هدفت الدراسة إلى التعرف على الانعكاسات الناتجة من توظيف استراتيجية الصف المقلوب في صفوف الرياضيات بالمرحلة الابتدائية على الممارسات التدريسية لمعلميها وأداء طلابهه. 
Ibrahim Alhoussain Khalil \& Omar saad Al- tmaran \& Abdulhamid essa Hashmi

Volume (4) No. (1) 2021

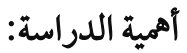

تقدم الدراسة مجموعة من الانعكاسات الناتجة من توظيف استراتيجية الصف المقلوب في صفوف الرياضيات بالمرحلة الابتدائية، إضافة إلى تقديم بجموعة من مقاطع الفيديو لدروس وحدة العمليات على الكسور الاعتيادية.

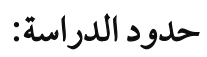

الحدود الموضوعية: طبّبّت استراتيجية الصف المقلوب عند تدريس وحدة العمليات على الكسور الاعتيادية المضمنة في كتاب الرياضيات بالفصل الدراسي الثاني للصف السادس الابتدائي.

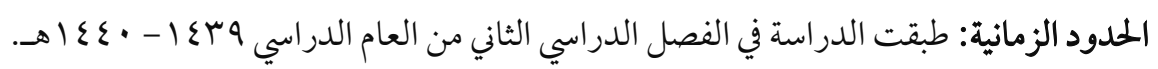
الحدود البئرية: طُبتت الدراسة على بجموعة من معلمي الرياضيات بالصفوف العليا للمرحلة الابتدائية وطلابهم.

الحدود المكانية: طبقت الدراسة في مدرستين: إحداهما تابعة لإدارة التعليم في صبيا، والأخرى في إدارة

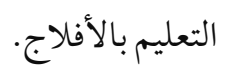

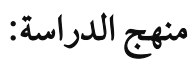

استخدمت الدراسة المنهج النوعي (دراسة حالات متعددة) لملاعمته لأهداف الدراسة الذي

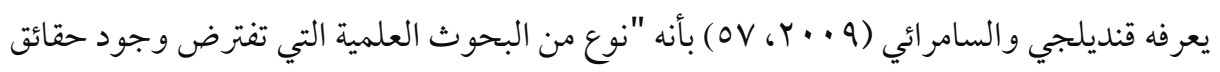

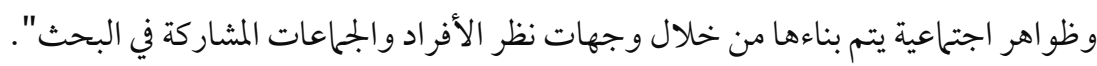

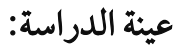

يرتبط حجم العينة في البحث النوعي بهدف الدراسة، والاستراتيجيات المتبعة لجمع البيانات، وتعتمد الأفكار التي يتم الحصول عليها في البحث النوعي على توفر المعلومات، والقدرات التحليلية للباحث أكثر منها على حجم العينة أو عدد الأشخاص، ويمكن أن يتراوح حجم العينة المقصودة ما بين

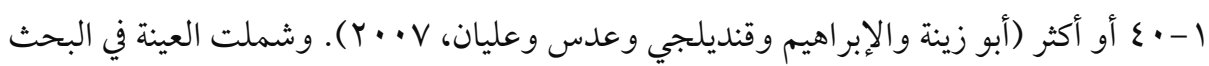


د. إبراهيم بن الحسين خليل \& أ. عمر بن سعد التمر ان \& عبدالحميد بن عيسى هاشمي المجلد (4) العدد (1) 2021م

الحالي اثنين من معلمي الرياضيات بالصفوف العليا للمرحلة الابتدائية، و(rع) طالبًا من طلاب الصف السادس الابتدائي، وصفها على النحو الآتي:

جدول (1) وصف عينة الدراسة المتعلقة بمعلمي الرياضيات بالمرحلة الابتدائية (الأسماء مستعارة)

\begin{tabular}{|c|c|c|c|c|}
\hline النصاب التدريسي & المؤهل & سنوات الملبرة & إدارة التعليم & المعلم \\
\hline$r$. & ماجستير & 17 سنة & صبيا & J.J \\
\hline 10 & ماجستير & 1 سنوات & الأفلاج & ن. \\
\hline
\end{tabular}

جدول (Y) وصف عينة الدراسة المتعلقة بطلاب الصف السادس الابتدائي

\begin{tabular}{|c|c|c|c|}
\hline معدل العمر & العدد & إدارة التعليم & المدرسة \\
\hline Ir & $r \cdot$ & صبيا & (1) \\
\hline ir & Yr & الأفلاج & (Y) \\
\hline
\end{tabular}

يبين الجمول ( ( )، و (Y) تفاصيل عينة الدراسة حيث كان المعلم (ل.ر ) من منسوبي إدارة تعليم

صبيا وخبرته التدريسية 7 العامًا حاصل على درجة الماجستير ونصابه التدريسي · r حصة، بينما ينتمي المعلم الآخر (ن.ع) لإدارة تعليم الأفلاج وخبرته التدريسية ^ سنوات وحاصل على درجة الماجستير ونصابه التدريسي 10 حصة، في الجانب الآخر بلغ عدد الطلاب الذين طبقت عليهم التجربة في المدرسة الأولى ( • Y) طالبًا من طلاب الصف السادس، بينما بلغ عدد الطلاب في المدرسة الثانية (Y Y) طالبًا. تم اختيار العينة بطريقة قصدية للأسباب الآتية: لتباين الخبرة التدريسية، اختلاف المنطقة التعليمية، استعداد المعلمين واهتمامهم بتطبيق التجارب العلمية، قناعتهم بأهمية البحث العلمي في تطوير الميدان التعليمي، خبرتهم التدريسية في المرحلة الابتدائية.

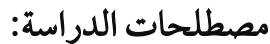

استراتيجية الصف المقلوب: يعرفها زنقور (Y. V V بأنه عبارة عن عملية يُعرض -من خلالها- محتوى تعليمي من خلال التقنية، حيث يتاح للطالب عرض الدرس والأنشطة والاختبارات قبل دخول الحصة الدراسية؛ ليستفاد من زمن الحصة كاملة لمراجعة ما شوهد ومناقشته. 
Ibrahim Alhoussain Khalil \& Omar saad Al- tmaran \& Abdulhamid essa Hashmi Volume (4) No. (1) 2021

ويعرفها الباحثون إجر ائيا: بأنها استراتيجية تستند على فلسفة التعلم النشط، والتعلم المتمركز على المتعلم، إذ يتابع الطالب الفيديوهات التعليمية المتعلقة بوحدة العمليات على الكسور الاعتيادية بالاعتماد على نفسه، والتحضير للحصة الدراسية، وإنهاء التكليفات المطلوبة؛ ليناقش جميع الأفكار المتعلقة بالدرس، ويتاح للمعلم تحسين ممارساته التدريسية في الحصة الدراسية.

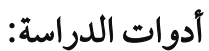

$$
\text { لتحقيق أهداف الدراسة، استخدمت الأدوات الآتية: }
$$

1- مفكرة معلم: إذ كان الهدف من المفكرة أن يرصد المعلمان تحركات الطلاب وانطباعاتهم بشكل يومي حول الاستراتيجية، إضافة لرصدهم لانعكاسات التجربة على ممارساتهم التدريسية بشكل يومي، ومتابعة التطور اليومي في الممارسات التدريسية. r- بطاقة ملاحظة المشارك: لرصد أراء الطلاب وتفاعلهم مع التجربة. r- المقابلات : تنوعت طر ائق جمع البيانات باستخدام المقابلة، وكانت على النحو الآتي:

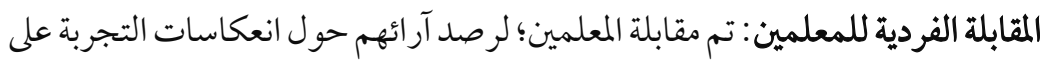
ممارساتهم التدريسية الصفية، وعلى طلابهم، إضافة إلى مقابلة بجموعة من الطلاب؛ لمعرفة آرائهم حول التدريس باستخدام استراتيجية الصف المقلوب. حيث تم مقابلة المعلمين بواقع (YY) مقابلة، بو اقع (11) مقابلة لكل معلم، (9) مقابلات كانت بشكل يومي وتدور المناقشة حول ما دونه المعلم في المذكرة اليومية وطلب استيضاحات وشو اهد حول بعض الآراء، بينما أضيفت مقابلتان لكل معلم بعد انتهاء التجربة؛ لمناقشة مرئياتهم عن التجربة بشكل عام و التأكد من آرائهم السابقة. المقابلة الجماعية والفردية (للطلاب): نفذت أثناء الحصة الدراسية بشكل يومي؛ لرصد آراء الطلاب حول الاستراتيجية، حيث تم توضيح آلية المقابلة للمعلم مع تحديد بعض المض بله النقاط اللازم التركيز عليها مثل (الدافعية، التحصيل)، مع إعطاء فرصة للطلاب للتعبير عن آرائهم دون قيود، بهدف الوصول لإيجابيات وانعكاسات التجربة من وجهة نظرهم. 
د. إبراهيم بن الحسين خليل \& أ. عمر بن سعد التمر ان \& عبدالحميد بن عيسى هاشمي المجلد (4) العدد (1) - 2021م

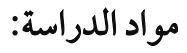

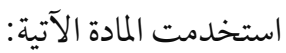

مقاطع الفيديو: إذ أنتجت (9) فيديوهات تعليمية، تتضمن دروس وحدة العمليات على الكسور الاعتيادية، حيث قام الباحثون بتصميمها وعرضها على بجموعة من معلمي الرياضيات لمر اجعة المحتوى العلمي والتحقق من الدقة العلمية المقدمة.

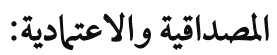

تستخدم مصطلحات المصداقية والموثوقية للبحوث التي تعتمد على الأدوات النوعية؛ لضمان منهجية علمية لجمع البيانات، وتحليلها، وتحري الموضوعية في البحوث الإنسانية (الصلاحي، \ل • ب).

المصداقية:

يقابل مصطلح المصداقية مصطلح الصدق الداخلي في البحث الكمي (العبدالكريم، Y ( • )، ويركز الصدق في البحث النوعي على تحقق الباحث من سلامة البيانات التي دوّنها من خلال عدة

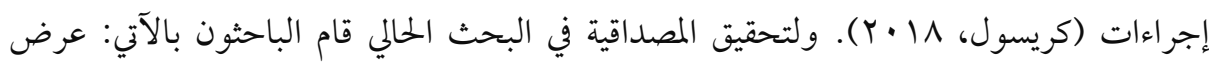

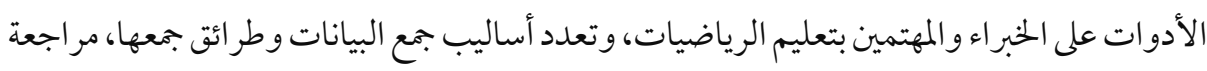
نتائج الدراسة وقراءتها، ومناقشتها مع المعلمين اللذين طبقا التجربة، ورصد الملاحظات في السياق الطبيعي، والرصد اليومي لآراء المعلمين والطلاب، ودمج البيانات من الأدوات المختلفة والربط بينها

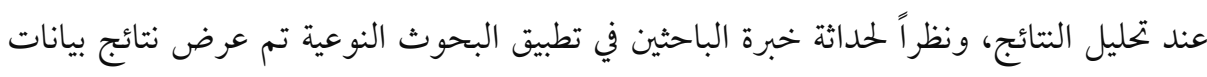

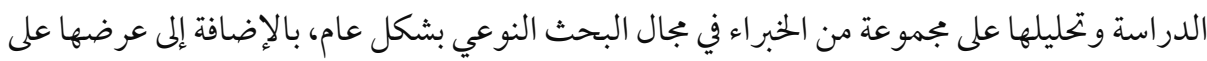
أحد الباحثين الذين لمم بحث نوعي سابق في توظيف استراتيجية الصف المقلوب في المرحلة الابتدائية.

الاعتحادية: - na

تقابل مصطلح الثبات في البحث الكمي، وقد أشار إلى هذا العبد الكريم (Y ا • r)؛ فالبحث الكيفي يرى أن الحقيقية الاجتماعية يعاد بناؤها باستمرار بشكل متجدد، وعليه فمفهوم إعادة تطبيق

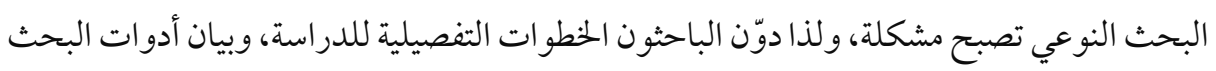


Ibrahim Alhoussain Khalil \& Omar saad Al- tmaran \& Abdulhamid essa Hashmi Volume (4) No. (1) 2021

ومو اده بشكل تفصيلي، وطرائق استخدامهاو أهدافها، وربط نتائج الدراسة الحالية بالدراسات السابقة، إضافة إلى عرض تحليل النتائج على مجموعة من المهتمين و الخبراء بالبحث النوعي.

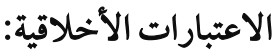

قبل البدء بتطبيق التجربة، تم التواصل مع المعلمين وقائدي المدارس في إدارتي التعليم، وتم تو ضيح آلية التطبيق ومدته المتوقعة وأهداف الدراسة والأدوات المستخدمة للدراسة ومو ادها، و التأكيد على عدم إظهار الأسماء الحقيقية للمشاركين واستخدام الأسماء المستعارة.

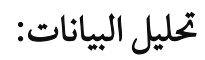

استُخدم أسلوب التحليل الموضوعي (Thematic analysis) الذي يتيح للباحث تحديد الموضوعات وعرضها بطريقة منهجية من خلال التركيز على البيانات، وتحديد المعاني المشتركة المستخلصة من البيانات (Braun, Clarke, 2012)، وقد مرت عملية التحليل بعدة مر احل: ا. . تحليل عدد من الدراسات العلمية التي تناولت توظيف استراتيجية الصف المقلوب في صفوف الرياضيات تحديدًا للاستفادة من نتائج الدراسة وتحديد الموضوعات التي يمكن التركيز عليها عند المقابلات والملاحظة و تحليل البيانات، مثال ذلك: تحديد التحصيل

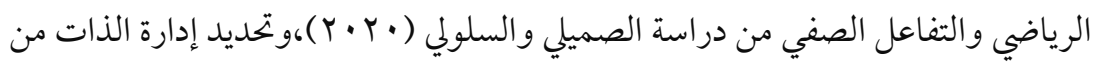
دراسة ميور (Muir, 2015). r. عمل مقابلات مفتوحة ومتنوعة مع الطلاب والمعلمين وأولياء الأمور حول آرائهم عن انعكاسات التجربة، بالإضافة إلى ما يدون من ملاحظات صفية يو مية من المعلمين. r. مراجعة ما تم جمعه من بيانات ومن ثم تدوينها مع ما يناسب من موضوعات تم تحديدها

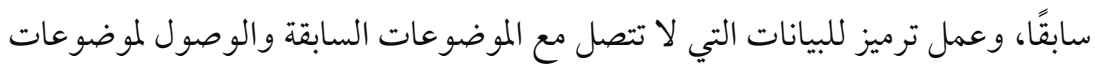
جديدة. ع. مراجعة الترميز والموضوعات الناشئة من الفريق البحثي عدة مرات؛ للتحقق من مدى الاتفاق حوها. 
د. إبراهيم بن الحسين خليل \& أ. عمر بن سعد التمر ان \& عبدا لحميد بن عيسى هاشمي

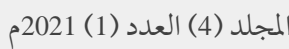

ه. الاعتماد على طريقة التثليث عند تحليل البيانات من خلال دمج الاستجابات الواردة في الأدوات المختلفة، والاستشهاد حرفياً أو بالفكرة لدعم التحليل وتحقيق الموضوعية.

\section{الإجابة عن أسئلة الدراسة ومناقشتها:}

\section{الإجابة عن السؤال الأول: ما انعكاسات توظيف استراتيجية الصف المقلوب في صفوف}

الرياضيات على الطلاب بالمرحلة الابتدائية؟ بعد جمع البيانات من خلال أدوات الدراسة المختلفة،

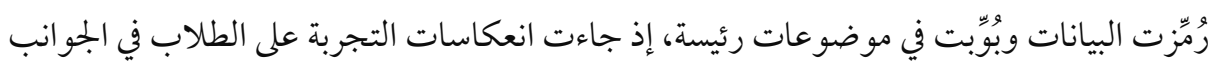

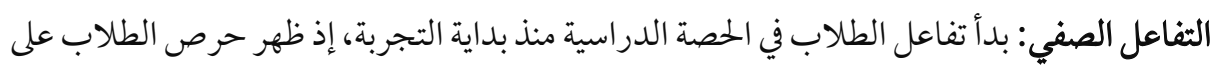
المناقشة والحديث عما تابعوه عن الموضوع الرياضي في الفيديو التعليمي الذي شاهدوه في منازهم، إذ إذ الذهي أشار المعلم (ن .ع) بأنه "اختلف معي تفاعل الطلاب في الحصة كليًا عن السابق". وذكر المعلم (ل. ر) "أصبح الطلاب يتسابقون على الحل"، ظهر كذلك بشكل ملحوظ التعلمُ المتمركز حول المتعلم وحرص الطلاب على الاستكشاف أثناء الحصة، إضافة لذلك ارتفع بشكل ملحوظ تو اصل الطلاب فيها بينهم وتبادل الأفكار والحلول فيما بينهم، وارتفع ذلك مع استمرار التجربة، وهذا يتفق مع دراسة بولي (Pulley, 2018) التي أشارت إلى ارتفاع نسبة تو اصل الطلاب فيها بينهم، وتو اصلهم مع المعلم، وتفاعلهم مع محتوى المادة العلمية.

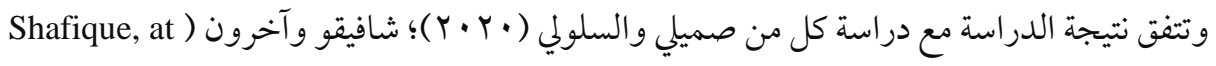
al, 2015$)$ (alsher, et al, 2018) فيشر وآخرون توصلت إلى دور استراتيجية الصف المقلوب في رفع مستوى التفاعل الصفي. الاتجاه نحو المادة: أسهمت الطريقة في جذب الطلاب لمتابعة الدرس أولاً بأول، وقد وجها أحد الطلاب سؤاله للمعلم قائلاً: "هل سندرس غداً بنفس الطريقة"، في إثارة إلى اتجاهه لتعلم المادة بهذه الاستراتيجية، وأشار طالب آخر إلى أن التدريس بأسلوب الصف المقلوب يسهل عليهم دراسة المادة وفهمها في وقت وجيز إذ قال "هذه الطريقة تجعلنا نتتهي من الدرس بسرعة ونحن فاهمون"، وذكر آخر 
من منخفضي التحصيل "الرياضيات أصبحت مادة سهلة"، إضافة إلى ذلك اتفق الطلاب على أنهم يعيدون متابعة الفيديوهات التعليمية بشكل مستمر، إضافة إلى رغبة الطلاب في استمرار حصة الرياضيات لوقت أطول. و أشار المعلم (ن.ع) "أصبحت ألاحظ حب الطلاب لي ولطريقة التدريس". إضافة إلى ذلك لوحظ اهتحام الطلاب بإخراج أعلاهم بشكل جميل، إذ أشار المعلم (ن.ع) "أصبح الطلاب ينوعون في ألو ان الأقلام لتزيين وتنظيم أعلالهم"، وأتبع ذلك بقوله "استراتيجية الصف المقلوب لعبت دورًا واضحًا في تغيير اتجاهات الطلاب نحو تعليم الرياضيات وتعلمها، وحب التفكير في الأسئلة لوجود وقت لذلك"، إضافة إلى ذلك لوحظ رغبة الطلاب في التكرار والمحاولة والمثابرة؛ لحل الأفكار المختلفة، وفي السياق نفسه أشار المعلم (ل.ر) إلى [أصبح الطلاب يتساءلون عن موعد [إرسال الفيديو التعليمي في قروب الواتساب] وتتفق نتيجة الدراسة الحالية مع نتيجة دراسة بيريس ( Pierce, 2013 التي توصلت إلى أن استراتيجية الصف المقلوب تجذب الطلاب للمادة الدراسية، وتتفق كذلك مع دراسة الحمداني وآخرون (-Al (Hamdani, et al, 2018 التعلم. الواجب المنزلي: انخفضت نسبة التأخر في حل الواجبات المنزلية بشكل ملحوظ، وبعد مرور التجربة

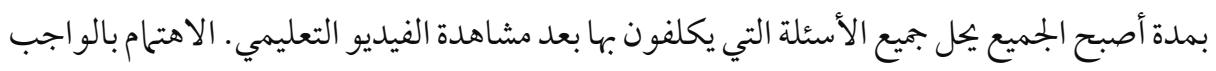
المنزلي لم يقتصر على الالتزام بالحل والتسليم، بل تعدى ذلك إلى طلب بعض الطلاب لمناقشة أفكار الو اجب في بجموعة الواتساب، وقد ذكر المعلم (ن.ع) [بعد مرور عدة حصص على التجربة أصبحت أقدم واجب لكل درس قبل حضور الخصة من خلال اعتماد الطلاب على مشاهدة الفيديو التعليمي، بالإضافة إلى واجب آخر بعد الانتهاء من الدرس في الخصة]. وقد أشار المعلم (ل.ر) إلى "أتاحت الاستراتيجية مناقشة الواجب المنزلي والتعرف على العقبات التي واجهت الطلاب، و الأخطاء المتكررة" تفاعل الأسرة: يوجد اتفاق تام من المعلمين على التحسن الملحوظ في تفاعل أولياء الأمور معهم، إذ أذ ذكرا بأن بعض أولياء الأمور يتمنون أن تدرس جميع المو اد بهذه الطريقة، إذ أشار أحد أولياء الأمور 
د. إبراهيم بن الحسين خليل \& أ. عمر بن سعد التمر ان \& عبدالحميد بن عيسى هاشمي المجلد (4) العدد (1) 2021م المعنين

[بأن هذه الطريقة تتيح لنا مراجعة الدرس بشكل سهل وواضح مع أبنائنا]، إضافة إلى ذلك أصبح العديد من أولياء الأمور يسألون عن مستوى طلابهم في كل درس، وعن المهات الجديدة.

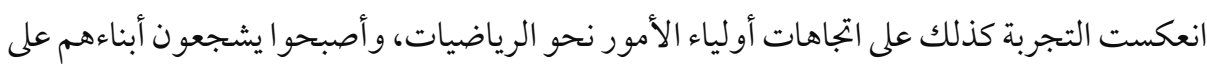

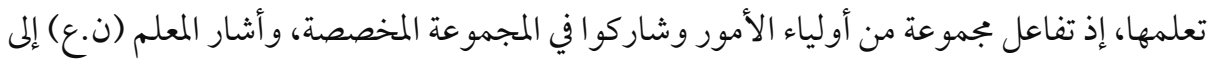

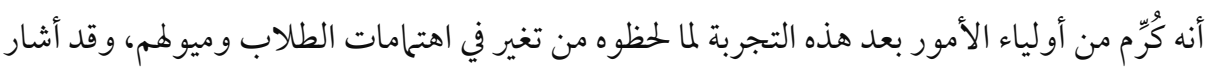

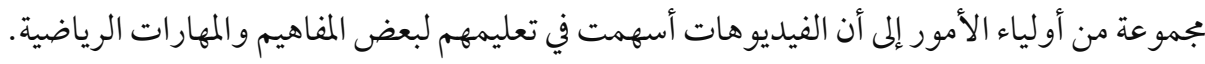

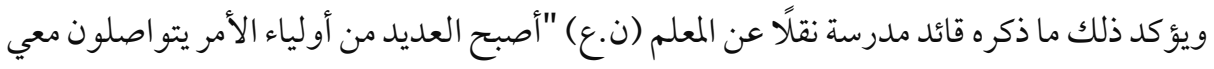

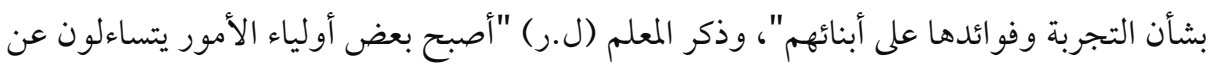

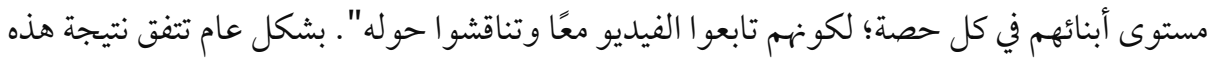

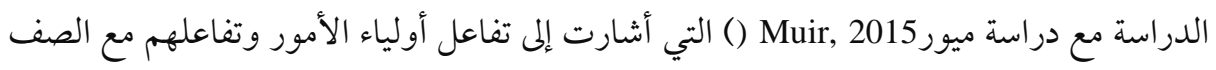
المقلوب، وأنهم يرون فائدته على فهم المحتوى ومر اجعة الدروس.

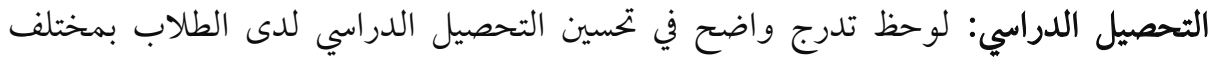

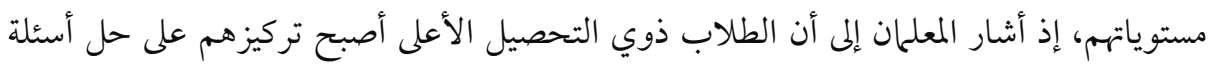

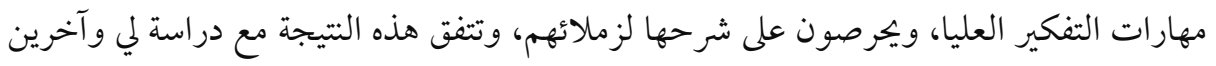
(Lai, et al, 2017) إضافة إلى حرصهم على شرح الدرس كل حصة بطلب منهم. بينما الطلاب ذوو التحصيل المتوسط

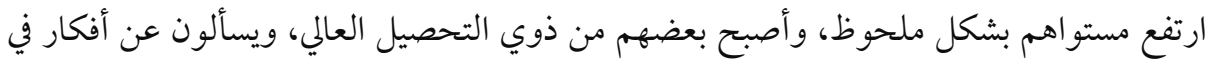

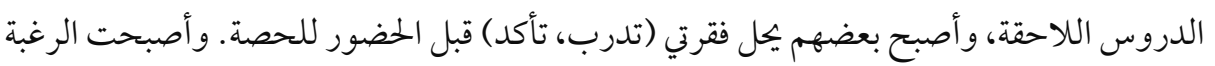

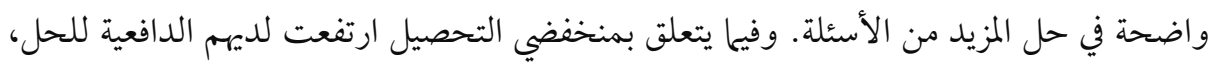

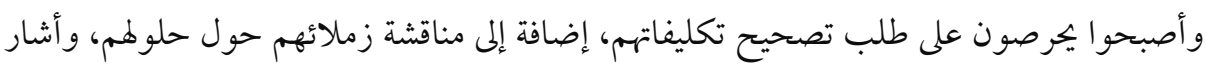

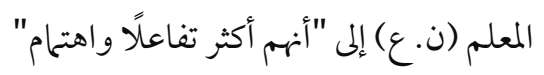


Ibrahim Alhoussain Khalil \& Omar saad Al- tmaran \& Abdulhamid essa Hashmi

Volume (4) No. (1) 2021

وفي السياق نفسه أشار أحد الطلاب من منخفضي التحصيل في الفترات السابقة بأنه سيصبح متفوقًا، إذ قال "في هذا الفصل سوف أحصل على متفوق"، الجدول الآتي يبين التصاعد في التحصيل الرياضي لدى الطلاب وفقا لمستوياتهم (منخفضي التحصيل، متوسطي التحصيل، مر تفعي التحصيل)، وفقًا للاختبارات التتابعية القصيرة في كل مدرسة.

$$
\text { جدول (r) متوسطات درجات الطلاب التتابعية وفقا لمتويات التحصيل }
$$

\begin{tabular}{|c|c|c|c|c|c|}
\hline المتوسط العام & الدرجات (Y) & الدرجات (Y) & الدرجات (1) & التحصيل & المدرسة \\
\hline$\varepsilon, v$ & $v, r$ & $\varepsilon, \wedge$ & $r, 1$ & التحصيل & \multirow{3}{*}{ (1) } \\
\hline 7,0 & $\wedge, 0$ & $\uparrow, \Lambda$ & $\varepsilon, \varepsilon$ & متتوسطي & \\
\hline$\wedge, 0$ & 9,0 & $\wedge, \uparrow$ & $v, r$ & مر تنغي التحصي & \\
\hline $0,1 r$ & $v, \varepsilon$ & $0, v$ & $r, r$ & التحصيل & \multirow{3}{*}{$(r)$} \\
\hline$T, \varepsilon r$ & $\wedge, r$ & 7,9 & $\varepsilon, 1$ & متوسطي & \\
\hline 1,07 & 9,1 & $\Lambda, \varepsilon$ & $v, 0$ & مرتفعي التحصي & \\
\hline
\end{tabular}

يتضح من الجدول (r) التصاعد في متوسطات درجات الطلاب في المدرستين وفقا لمستويات

التحصيل الرياضي (منخفضي التحصيل، متوسطي التحصيل، مرتفعي التحصيل)؛ حيث أجريت اختبارات قصيرة أثناء تطبيق التجربة؛ بهدف معرفة مدى التقدم في مستويات الطلاب، والأشكال الآتية تبين المقارنات بين المتوسطات وفقا لمستويات الطلاب في كل مدرسة. 
د. إبراهيم بن الحسين خليل \& أ. عمر بن سعد التمر ان \& عبدالحميد بن عيسى هاشمي المجلد (4) العدد (1) 2021م

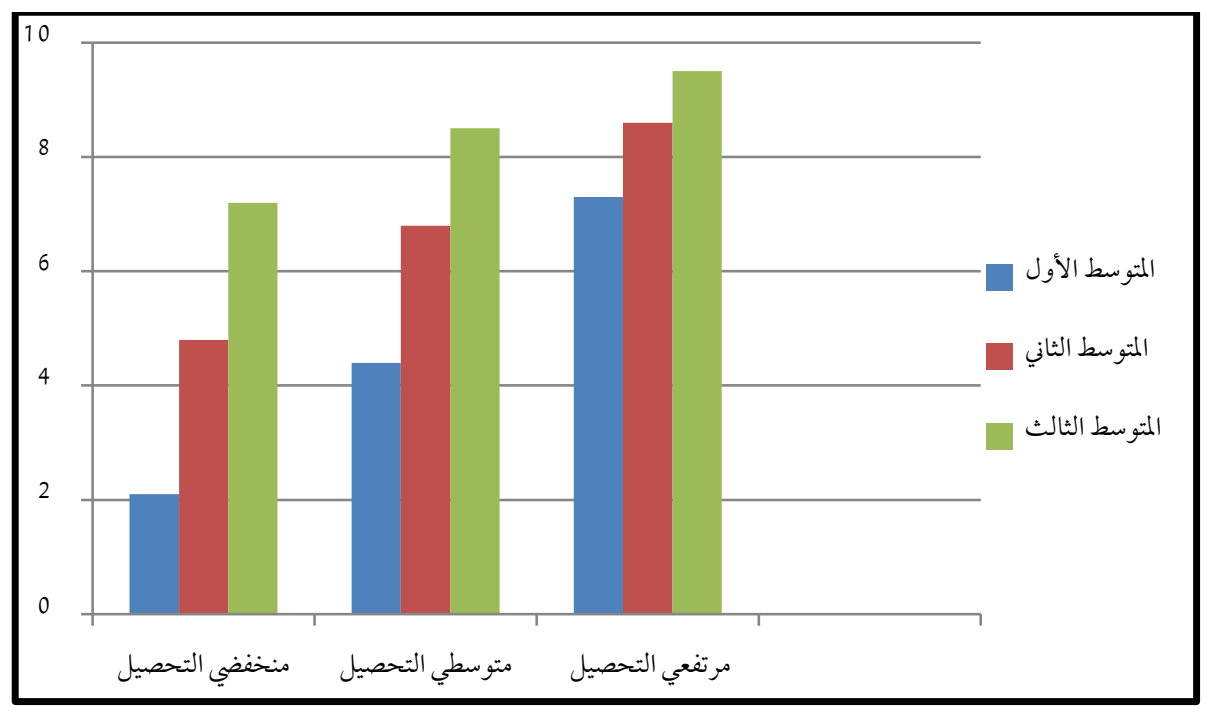

شكل ( ) المقارنة بين متوسطات درجات الطلاب وفقا لمستوياتهم في المدرسة الأولى

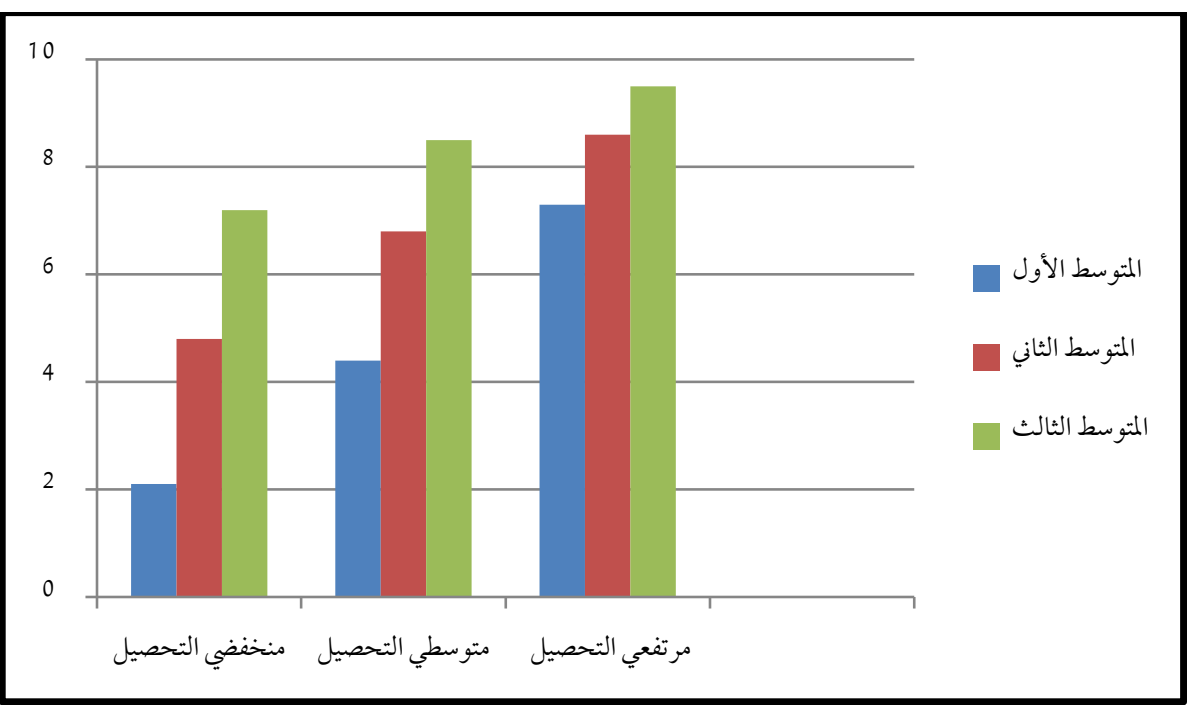

شكل (Y) المقارنة بين متوسطات درجات الطلاب وفقا لمستوياتهم في المدرسة الثانية

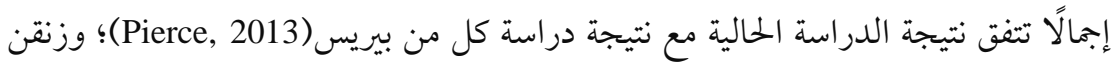

(Zengin, 2017)؛ والحمداني وآخرون (Al-Hamdani, et al, 2018) صميلي والسلولي (·. (Y)

http://dx.doi.org/10.29009/ijres.4.1.12 
باغات وآخرين (Bhagat, et al, 2018) ؛الشهري(9 ( + ) التي توصلت إلى فاعلية استراتيجية الصف المقلوب في تنمية التحصيل الرياضي وفهم المحتوى التعليمي. تقدير الذات الرياضي: استعان الباحثون بمجموعة من أسئلة المقابلة شبه المقننة إضافة إلى الملاحظة الصفية أثناء الحصة، إذ اتفق الطلاب على أن الاستراتيجية أسهمت في تعلمهم الذاتي ومر اجعة الدروس بشكل مستمر كلم) دعت الحاجة، وفي هذا السياق ذكر مجموعة من الطلاب [نحن الآن لا نحتاج لمعلم خصوصي وقت الاختبارات النهائية في دروس الكسور]. كما لوحظ ازدياد الثقة في طرح الطلاب ومناقشاتهم في الحصة، ويعود السبب للخلفية المعرفية عن الموضوع قبل دخول الحصة، إضافة إلى ذلك تفاعل الطلاب في المناقشات المتنوعة، إذ أشار مجموعة من الطلاب إلى [أصبحنا نناقش المعلم بأريحية ونتحمس للمشاركة والمناقشة في الحصة]، وفي السياق نفسه أكد المعلم (ل.ر) ما ذكره الطلاب "الاستراتيجية تزيل الرهبة من الخطأ في الحصة" وقد أشار المعلم (ن.ع) إلى "أسهمت الاستراتيجية في تنمية مهارة اتخاذ القرار لدى الطلاب" وتتفق نتيجة الدراسة مع دراسة فيشر وآخرين ( Fisher, et al, 2018 التي توصلت إلى اسهام استراتيجية الصف المقلوب في رفع مستوى الرضاء عن الأداء. وتتفق مع دراسة باغات وآخرين (Bhagat, et al, 2018) وآخرين ( Sun, et al, 2018 في فاعلية الصف المقلوب في زيادة الثقة في النفس، ومع دراسة هوانق وآخرين (Hwang, et al, 2017) التي تو صلت إلى فاعلية استراتيجية الصف المقلوب في تنمية الكفاءة الذاتية لدى المتعلمين. الإجابة عن السؤال الثاني: ما انعكاسات توظيف استراتيجية الصف المقلوب في صفوف الرياضيات على الممارسات التدريسية لدى معلمي الرياضيات بالمرحلة الابتدائية العليا؟

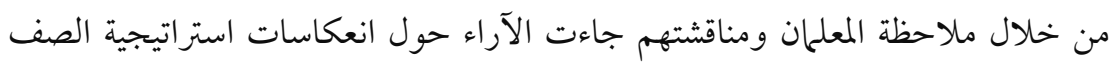
المقلوب على قسمين: الأول: عند التحضير والإعداد للدرس، والآخر: أثناء الحصة الدراسية، تفصيلها كالآتي: 
د. إبراهيم بن الحسين خليل \& أ. عمر بن سعد التمر ان \& عبدا لحميد بن عيسى هاشمي

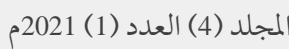

عند التحضير والإعداد للدرس: يوجد اتفاق تام من قبل المعلمان على أن استراتيجية الصف المقلوب تتطلب إعداداً مسبقاً وجهدًا ووقتًا، وهذا يتفق مع ما ذكره شين وآخرون (Chen, et al, 2017 )؛ ومتولي ( 10 • ( أن من التحديات التي تواجه المعلمين عند توظيف استراتيجية الصف المقلوب الإعدادَو التحضير. إلا أن هذا الوقت في التحضير ينعكس إيجابًا على وقت الحصة، إذ يتيح الاستفادة من وقت الخصة بشكل أفضل، وقد أشار المعلم (ل.ر) "الإعداد للحصة في الصف المقلوب مسؤولية

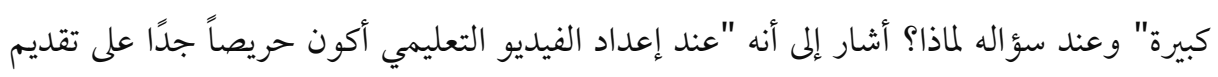
المعلومات بشكل صحيح؛ مما يستدعي الإعداد والقراءة الجيدة لتفاصيل الدرس؛ لكون الفيديو التعليمي سيتداول بين الطلاب وأولياء الأمور". إضافة إلى ذلك اتفق المعلمان على أن الإعداد في الصف المقلوب يدعم التفكير في اختيار

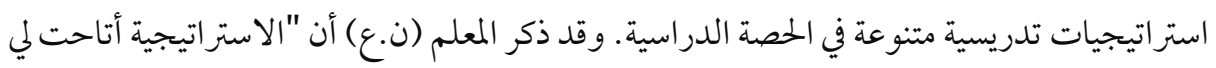
مراعاة الفروق الفردية عند الإعداد للدرس الجديد" وأضاف "الصف المقلوب ييعلني متشوقًا للحصة"

أثناء الحصة الدراسية: ساعدت الاستراتيجية المعلمين على تنفيذ الدرس بيسر وسهولة وتغطية جميع

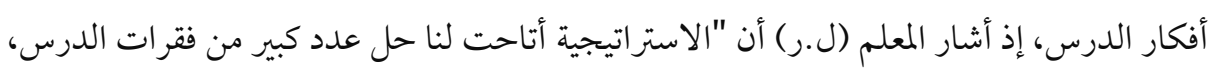
وقللت وقت مراجعة أفكار الدروس السابقة"، واتفق المعلمان على أن الاستراتيجية خففت عنهم العبء التدريسي، وقللت التعليم المباشر، إضافة لذلك استُخِدمت العديد من الاستراتيجيات

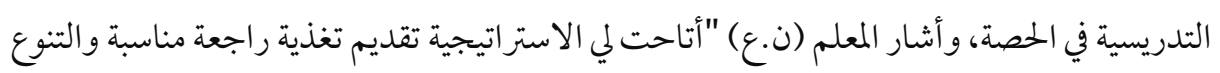
في أساليب التقويم"، وأشار المعلم (ل.ر) "أتاحت لي الاستراتيجية حل العديد من المشكلات الصفية". وتتفق نتيجة الدراسة الحالية مع دراسة كل من شافيقو وآخرين (Shafique, et al, 2015 )؛ (م) وأوزداملي وآخرين ( Ozdamli, et al, 2016$)$ بولي (Pulley, 2018) التي أشارت إلى أن استراتيجية الصف المقلوب تسهم في تقليل التعلم المباشر وزيادة وقت الخصة، وتتيح للمعلم استخدام إستراتيجيات وأنشطة متنوعة. 
Ibrahim Alhoussain Khalil \& Omar saad Al- tmaran \& Abdulhamid essa Hashmi

Volume (4) No. (1) 2021

استتاجات (فروض) بعد تطبيق التجربة:

يدعم الصف المقلوب التفاعل الصفي.

يدعم الصف المقلوب تفاعل الأسرة مع المعلم.

يدعم الصف المقلوب رفع مستوى التحصيل الدراسي.

يدعم الصف المقلوب الاتجاه نحو الرياضيات وتعلمها.

يسهم الصف المقلوب في تقدير الذات الرياضي.

يسهم الصف المقلوب في التغلب على تأخر الطلاب في حل الواجبات، والتو اصل فيما بينهم.

يسهم الصف المقلوب في الاهتحام بالإعداد الجيد للدرس مما ينعكس على أداء المعلم.

يتيح الصف المقلوب الاستفادة من الوقت في حل المشكلات الصفية وتنمية مهارات التفكير

العليا.

قصور الدراسة: - ق

وُظظّفت الاستراتيجية في مدرستين فقط، ومعلمين، ويمكننا توسيع العينة.

ناقشت الدراسة مجموعة متغيرات بالاستناد على دراسات سابقة، بالإضافة إلى متغيرات

$$
\begin{aligned}
& \text { أخرى ظهرت أثناء التجربة في الظروف الطبيعية. } \\
& \text { استمرت التجربة لمدة (ع ) أسابيع تقريبًا. }
\end{aligned}
$$

يعد هذا البحث الأول للباحثين في المنهج النوعي، مما يعني قلة الخبرة في هذا النوع من

$$
\text { البحوث. }
$$

تباعد المدرستين التي يعمل فيها المعلمان عن بعضها قلل من فرصة اللقاءات الجماعية

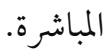

واجه المعلمان تحديات في التنسيق بين المدرسة وأولياء الأمور بداية التجربة. واجه المعلم|ن صعوبة في بداية التجربة في كتابة التقارير اليومية حول التجربة وانعكاساها. 
د. إبراهيم بن الحسين خليل \& أ. عمر بن سعد التمر ان \& عبدالحميد بن عيسى هاشمي المجلد (4) العدد (1) 2021م المعنين

قلة وجود الفرص المتكافئة بين الطلاب من حيث امتلاك بعضطم للأجهزة الذكية التي تقلل من التواصل مع المعلم ومشاهدة الفيديوهات التعليمية. التوصيات: بناء على نتائج الدراسة يمكن تقديم التوصيات الآتية: 1- ت تدريب المعلمين على الإلمام بالتقنية التي تسهل إنتاج الفيديوهات التعليمية. r- ت تدريب المعلمين على توظيف استراتيجية الصف المقلوب في المراحل الدراسية المختلفة.

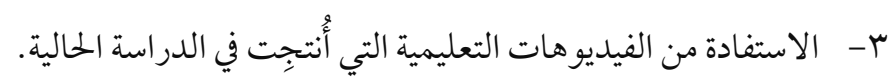

المقترحات

في ضوء نتائج الدراسة يمكن تقديم المقترحات الآتية: 1 - دراسة معتقدات المعلمين حول استراتيجية الصف المقلوب. ץ- دراسة مقارنة بين استراتيجية الصف المقلوب واستراتيجيات تدريسية حديثة أخرى. ب- دراسة احتياجات المعلمين التدريبة؛ لتوظيف استراتيجية الصف المقلوب. ع - دراسة التحديات و المعيقات التي تواجه المعلمين عند توظيف الصف المقلوب. 0- قياس فاعلية استراتيجية الصف المقلوب على متغيرات حديثة. 7- دراسة توظيف استراتيجية الصف المقلوب في مراحل التعليم المختلفة. 


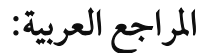

ا ـ أبو زينة، فريد كامل والإبراهيم، مروان وقنديلجي، عامر وعدس، عبد الرممن وعليان، خليل.

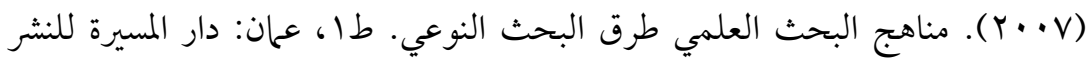

$$
\text { و التوزيع والطباعة. }
$$

r. . آل معدي، عبد العزيز بن سعيد . (10 • ؟). فاعلية استخدام التعلم المددج بالصفوف المقلوبة في

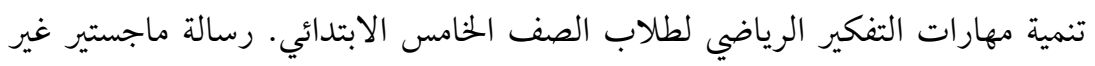
منشورة، كلية العلوم الاجتماعية، جامعة الإمام عمد بن سعود الإسلامية.

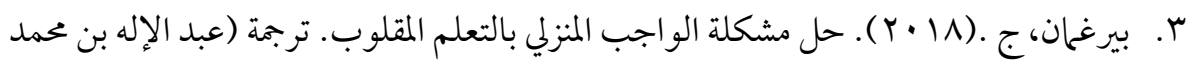

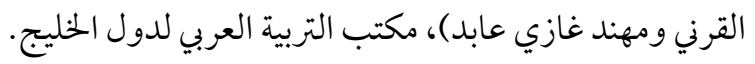

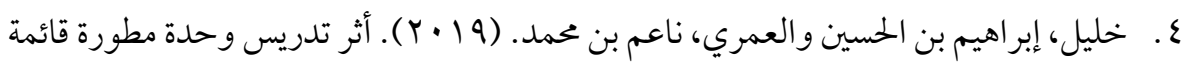
على بعض مهارات القرن الحادي والعشرين في تنمية التحصيل الدراسي وتقدير الذات

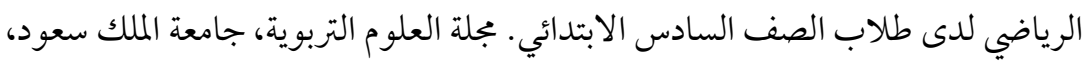

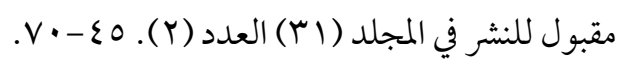

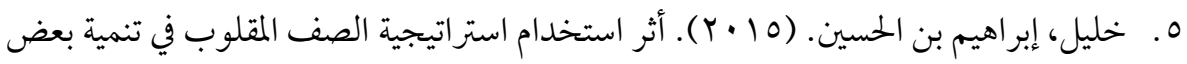
مكونات التعلم المنظم ذاتياو الاتجاه نحو المادة لدى طلاب الصف السادس الابتدائي. دراسة

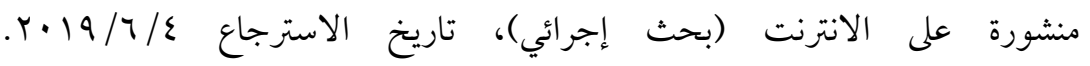
https://www.researchgate.net/profile/Ibrahim_Khalil23/publication/3042701 20_bhth_ajrayy_athr_astkhdam_astratyjyt_alsf_almqlwb_fy_tnmyt_bd_mkw nat_altlm_almnzm_dhatya_walatjah_nhw_almadt_ldy_tlab_alsf_alsads_alab tdayy/links/576b629b08aef2a864d211be.pdf T. . خليل، إبراهيم بن الحسين. (19 (Y) . فاعلية وحدة تعليمية مقترحة قائمة على نموذج التكامل

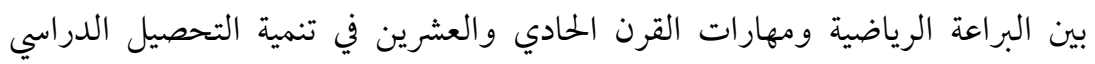

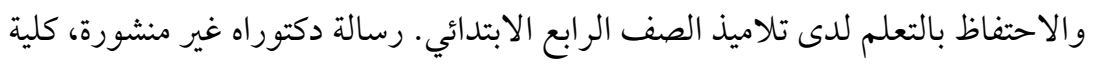

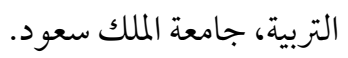


د. إبراهيم بن الحسين خليل \& أ. عمر بن سعد التمر ان \& عبدالحميد بن عيسى هاشمي المجلد (4) العدد (1) 2021م

V. الدوخي، فوزي عبد اللطيف (YV) (Y). أثر استراتيجية التعلم المقلوب على زيادة التحصيل العلمي لدى الطلبة ذوي صعوبات التعلم في فصول الدمج وتقليل فترات دراستهم في غرف

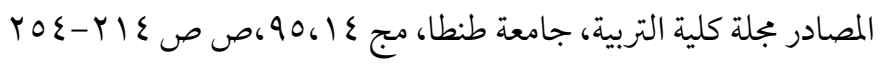

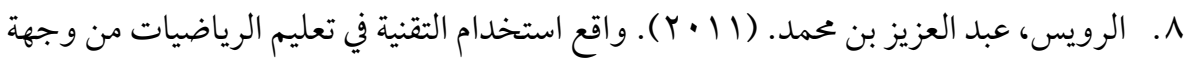
نظر معلميها للمر حلة المتوسطة في المملكة العربية السعودية. رسالة الخليج العربي، (I I )، $.07-10$

9 ـ زنقور، ماهر محمد . (Y) (Y). بيئة الصف المقلوب لتنمية مهارات التفكير الحدسي ومستويات الاستدلال التناسبي في الرياضيات لدى طلاب المرحلة المتوسطة خختلفي السيطرة الدماغية.

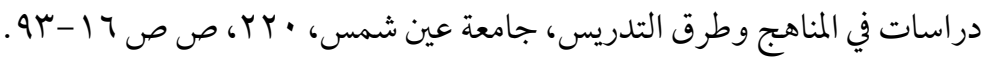
• ا. الشهري، مانع بن علي. (9 ( ب). فاعلية استخدام الفصل المعكوس في التحصيل وتنمية مهارات الحس العددي لدى طلاب الصف الخامس الابتدائي. بجلة جامعة بيشة للعلوم

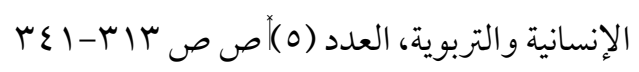
1 ا ـ الصلاحي، سعود بن موسى. (1 ( • ) . إضاءات بحثية تدوينات مهمة لطلبة الدراسات العليا و المهتمين بالبحث. ط ب، الرياض: مكتبة الرشد ناشرون.

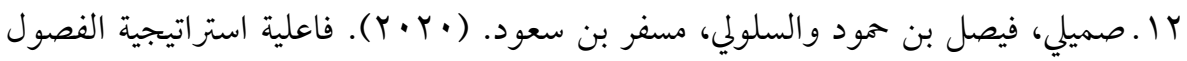
المقلوبة في تنمية التحصيل الرياضي والتفاعل الصفي لدى طلاب الصف الثالث الثانوي.

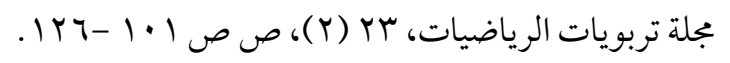

rا ـ العبد الكريم، راشد بن حسين. (Y • (Y). البحث النوعي في التربية. الرياض: مطابع جامعة

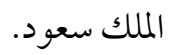

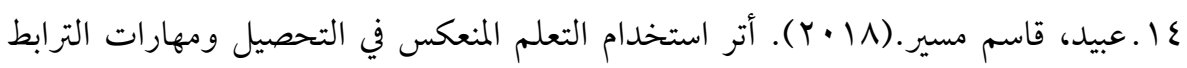
الرياضي لدى طلاب الصف الرابع العلمي في مادة الرياضيات. رسالة ماجستير غير منشورة، كلية التربية للعلوم الصرفة - ابن الهيثم، جامعة بغداد. 
Ibrahim Alhoussain Khalil \& Omar saad Al- tmaran \& Abdulhamid essa Hashmi Volume (4) No. (1) 2021

ه ـ العنزي، عبد العزيز بن رواف والنذير، محمد بن عبد الله. (7 ( ·). درجة اكتساب تلاميذ الصف السادس الابتدائي المعرفة الرياضية الأساسية المضمنة مقرر الرياضيات. المجلة

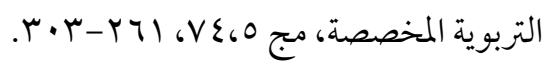

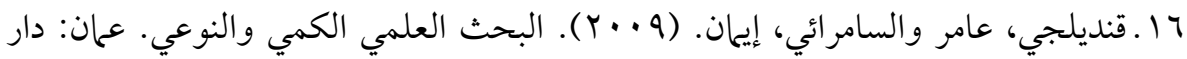
اليازوري العلمية للنشر والتوزيع.

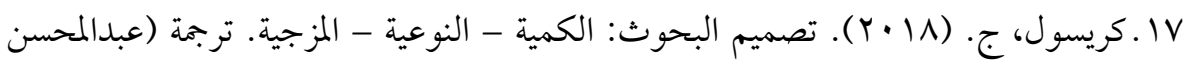
عايض القحطاني). الكويت: دار المسيلة للنشر والتوزيع.

1 1 ـ المالكي، مفرح مسعود و المقوشي، عبد الله بن عبد الرحن. (7 1 ). واقع تدريس الرياضيات

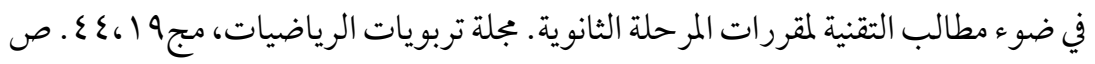

$$
\text { ص }
$$

9 1 اـمتولي، علاء الدين سعد. (10 • Y). توظيف استراتيجية الفصل المقلوب في عمليتي التعليم والتعلم ورقة عمل المقدمة إلى المؤتمر العلمي السنوي الخامس عشر للجمعية المصرية لتربويات الرياضيات (تعليم وتعلم الرياضيات وتنمية مهارات القرن الحادي والعشرين)،

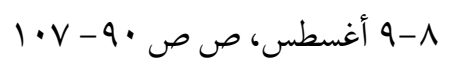

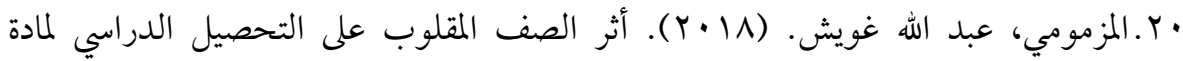

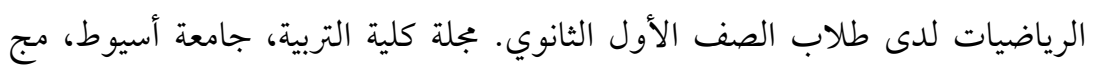

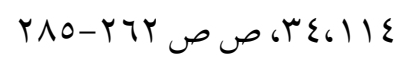

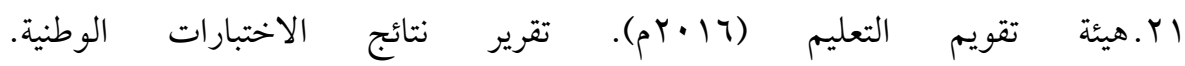
http://eec.gov.sa/results/nap/student 


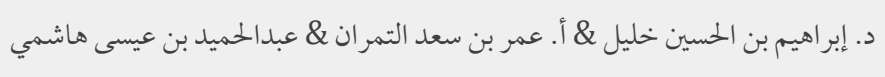

المجلد (4) العدد (1) 2021م

\section{References:}

- Alrouqi, f.(2019). Using Flipped Classrooms to Teach Mathematics to Elementary Students in Saudi Arabia. Phd Dissertation, University of South Florida.

- National Council of Teachers of Mathematics (NCTM). (2000). Curriculum and Evaluation Standards for School Mathematics. Reston, VA: NCTM.

- Trends in International Mathematics and Science Study (TIMSS). (2012). TIMSS 2011 International Results

- $\quad$ Trends in International Mathematics and Science Study. TIMSS,2015.

- $\quad$ Ozdamli, F. \& Asiksoy, G. (2016). Flipped classroom approach. World Journal on Educational Technology: Current Issues. 8(2), 98-105.

- $\quad$ Dove, A. \& Dove, E. (2014). Examining the influence of a flipped classroom approach in mathematics. Proceedings of Society for Information Technology \& Teacher Education International Conference 2014. 12301236.

- Shafique, M \& Irwin-Robinson , H .(2015). A Study on the Effectiveness of Flipped Teaching in College Math Classroom. International Journal of Education and Information Technology Vol(1) 2, 2015, pp. 29-33.

- $\quad$ Farmer, R .(2018). The What, the How and the Why of the Flipped Classroom. Innovative Practice in Higher Education, Vol (3) 2, pp 14-31.

- Pierce, R. (2013). Student Performance in a Flipped Class Module. In R. McBride\& M. Searson (Eds.), Proceedings of Society for Information Technology\& Teacher Education International Conference 2013 (pp. 942 954). Chesapeake, VA: AACE. Retrieved October 17, 2013.

- $\quad$ Fisher, R ; Perényi; Á \& Birdthistle, N. (2018). The positive relationship between flipped and blended learning and student engagement, performance and satisfaction. Active Learning in Higher Education,pp $1-17$.

- $\quad$ Sakar, D \& Sağır, S .(2017). Flipped classroom model in education. International Journal of Social Sciences and Education Research, 3(5),PP 1904-1916. 
- $\quad$ Lai, Y \& Lee, K .(2017). Facilitating higher-order thinking with the flipped classroom model: a student teacher's experience in a Hong Kong secondary school. Research and Practice in Technology Enhanced Learning. PP 1-14. file:///C:/Users/LaYaN/Desktop/filliped\%20classroom/7.pdf

- Al-Hamdani, D. \& Al Breiki, M.(2018). THE EFFECT OF FLIPPED VOCABULARY LEARNING ON ACHIEVEMENT AND ATTITUDES OF EFL NINTH-GRADERS IN OMAN. International Journal of Research in Applied, Natural and Social Sciences, vol(6) 10, PP 35-44

- $\quad$ Bhagat, K, Chang, C, \& Chang, C. (2016). The Impact of the Flipped Classroom on Mathematics Concept Learning in High School. Educational Technology \& Society, vol 19 (3), pp 134-142.

- $\quad$ Lai,C\& Hwang, G .(2016). A self-regulated flipped classroom approach to improving students' learning performance in a mathematics course. Computers \& Education, Vol (100), PP 126-140.

- Chen, G; Hew, K \& Lo, C. (2017). Toward a set of design principles for mathematics flipped classrooms: A synthesis of research in mathematics education. Educational Research Review, Vol (22), PP 50-73.

- Muir, T. (2015). Student and Parent Perspectives on Fipping the Mathematics Classroom. Paper presented at the Annual Meeting of the Mathematics Education Research Group of Australasia (MERGA) (38th, Sunshine Coast, Queensland, Australia, 2015)

- $\quad$ https://files.eric.ed.gov/fulltext/ED572477.pdf

- Hwang, G \& Lai, C. (2017). Facilitating and Bridging Out-Of-Class and In-Class Learning: An Interactive E-BookBased Flipped Learning Approach for Math Courses. Educational Technology \& Society, vol 20 (1), 184-197.

- $\quad$ https://www.j-ets.net/ets/journals/20_1/17.pdf

- $\quad$ Sun, Z ; Xie, K \& Anderman, L. (2018). The role of self-regulated learning in students' success in flipped undergraduate math courses. The Internet and Higher Education, vol (36) 1, PP 41-53. 


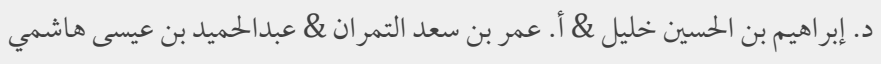

- $\quad$ www.maktabe-hekmat.ir/wp-content/uploads/2018/12/2018.-FC-in-mathcourses.pdf

- Villaba, T; Castilla, G \& Redondo- Duarte, S. (2018). FACTORS WITH INFLUENCE ON THE ADOPTION OF THE FLIPPED CLASSROOM MODEL IN TECHNICAL AND VOCATIONAL EDUCATION. Journal of Information Technology Education, Vol (17) 1, PP 441-469.

- $\quad$ Per, L \& Arne, S. (2018). Transitioning to Flipped Classroom-an experience report. Conference: NIK - Norsk InformatikkonferanseAt: Svalbard. file:///C:/Users/LaYaN/Desktop/filliped\%20classroom/14.pdf

- Foldnes, N. (2017). The impact of class attendance on student learning in a flipped classroom. Nordic Journal of Digital Literacy, Vol (12), PP 1-2

- file:///C:/Users/LaYaN/AppData/Local/Packages/Microsoft.MicrosoftEdge_8w ekyb3d8bbwe/TempState/Downloads/flipattend2\%20(1).pdf

- Ramakrishnan, N \& Priya, J. (2016). EFFECTIVENESS OF FLIPPED CLASSROOM IN MATHEMATICS TEACHING. International Journal of Research -Granthaalayah A Knowledge Repository, Vol (4) 10, PP 57-62.

- Cabi, E. (2018). The Impact of the Flipped Classroom Model on Students' Academic Achievement. Vol (19) 3, PP 202- 221.

- Zengin, Y. (2017). Investigating the Use of the Khan Academy and Mathematics Software with a Flipped Classroom Approach in Mathematics Teaching. Educational Technology \& Society,vol 20 (2), 89-100.

- Stöhr, C \& Adawi, T. (2018). Flipped Classroom Research: From "Black Box" to "White Box" Evaluation. Education Sciences. vol (8) 22, pp 1-4. file:///C:/Users/LaYaN/Desktop/filliped\%20classroom/35.pdf

- National Council of Teachers of Mathematics [NCTM]. (2014). Principles to Actions: Ensuring Mathematical Success for ALL.

- National Council of Teachers of Mathematics (NCTM). (2000). Curriculum and Evaluation Standards for School Mathematics. Reston, VA: NCTM. 
- $\quad$ Kim, S \& Chang, M. (2010). Does Computer Use Promote the Mathematical Proficiency of ELL Students? Journal of Educational Computing Research , vol 42(3), 285- 305.

- $\quad$ Sedique, A. (2017). School District Technology Awareness: A Descriptive Study Identifying Implications for the 21st-Century Teaching and Learning. Doctor of Education in Learning Technologies, Pepperdine University.

- $\quad$ Braun, V., \& Clarke, V.(2012).Thematic analysis. APA Handbook of Research Methods in Psychology, Vol 2: Research Designs: Quantitative, Qualitative, Neuropsychological, and Biological., 2, 57-71.

- $\quad$ Uzunbylu, H \& Prevalla, B .(2019). Flipped Learning in Engineering Education. TEM Journal, Vol (8) 2, PP 656-661.

- Pulley, P.(2018). INSIDE THE FLIP: A LOOK AT TEACHER MOTIVATIONS AND ACTIVITIES IN FLIPPED CLASSROOMS. Degree Of Doctor Of Education, Illinois State University. 
